\title{
Research Square \\ Effect of Low-Dose 18F-FDG on Image Quality in Digital PET/CT
}

Yuya Shirakawa ( $\nabla$ have_a_nice_day544@yahoo.co.jp )

Kyorin University Hospital

Original research

Keywords: digital PET/CT, dose, phantom, semiconductor, 18F-FDG

Posted Date: January 18th, 2022

DOI: https://doi.org/10.21203/rs.3.rs-1204228/v1

License: (a) (i) This work is licensed under a Creative Commons Attribution 4.0 International License. Read Full License 
Correspondence

5

6 Yuya Shirakawa

7 Radiological Technologist

8

9 Department of Radiology, Kyorin University Hospital,

10 6-20-2 Shinkawa, Mitaka, Tokyo, Japan 181-8611

11

12 E-mail: have_a_nice_day544@yahoo.co.jp

13 Tel: +81-422-47-5511

14 Fax: +81-422-76-0361

15

16 


\section{Abstract}

26 Patients in Japan undergoing PET/CT are injected with 3.7 MBq of ${ }^{18} \mathrm{~F}$-FDG which is a standard based on outdated

27 instrumentation. We investigated whether informative ${ }^{18} \mathrm{~F}-\mathrm{FDG}-\mathrm{PET} / \mathrm{CT}$ images of tumor glucose metabolism could

28 be acquired with lower ${ }^{18} \mathrm{~F}$ doses.

\section{Methods}

30 The background activity of a NEMA body phantom with $10-37-\mathrm{mm}$ hot spheres containing ${ }^{18} \mathrm{~F}-\mathrm{FDG}$ was set at 2.53

$31 \mathrm{kBq} / \mathrm{mL}(=3.7 \mathrm{MBq} / \mathrm{kg}$ dose; Hot $/ \mathrm{BG}=4$; standard $)$, and 1.73 and $1.34 \mathrm{kBq} / \mathrm{mL}(=2.5$ and $2.0 \mathrm{MBq} / \mathrm{kg}$ doses, respectively). Images were reconstructed using TOF-3D-OSEM and a Gaussian filter (GF) (FWHM 4 mm) and Clear

33 adaptive Low-noise Method (CaLM Mild). Image quality was evaluated as \% background variability $\left(\mathrm{N}_{\mathrm{B}, 10 \mathrm{~mm}), \%}\right.$ 34 contrast of 10-mm hot sphere $\left(\mathrm{Q}_{\mathrm{H}, 10 \mathrm{~mm}}\right)$, background coefficients of variation ( $\left.\mathrm{CV}_{\text {background }}\right)$, ratios of $\mathrm{Q}_{\mathrm{H}, 10 \mathrm{~mm}}$ to $\mathrm{N}_{\mathrm{B}, 10}$ $\mathrm{mm}\left(\mathrm{Q}_{\mathrm{H}, 10 \mathrm{~mm}} / \mathrm{N}_{\mathrm{B}, 10 \mathrm{~mm}}\right)$, and recovery coefficients (RC). The detectability of $10 \mathrm{~mm}$ hot spheres was evaluated at each 36 dose.

\section{$37 \quad$ Results}

38 The $\mathrm{N}_{\mathrm{B}, 10 \mathrm{~mm}}$ on images of $3.7 \mathrm{MBq} / \mathrm{kg}$ doses acquired for $270 \mathrm{sec}$ was 5.5\% (GF and CaLM Mild), which met the

39 guideline standard $(<5.6 \%)$, and $6.9 \%$ and $7.6 \%(\mathrm{GF})$ at 2.5 and $2.0 \mathrm{MBq} / \mathrm{kg}$ respectively, on images acquired for

$40300 \mathrm{sec}$, and $7.1 \%$ and $7.4 \%$ (CaLM Mild), which exceeded the standard.

41 The $\mathrm{Q}_{\mathrm{H}, 10 \mathrm{~mm}}$ indicated better contrast on images acquired for $120 \mathrm{sec}$ (clinical standard), with CaLM Mild, than the

42 GF. The $\mathrm{CV}_{\text {background }}$ values for $3.7 \mathrm{MBq} / \mathrm{kg}$ dose equivalents were $9.9 \%$ (GF) and 10\% (CaLM Mild) respectively,

43 for images acquired for 270 and $300 \mathrm{sec}$, which met the guideline criterion $(\leq 10 \%)$, and $11 \%$ and $12 \%(\mathrm{GF})$, and 
$4413 \%$ (CaLM Mild) for 2.5 and $2.0 \mathrm{MBq} / \mathrm{kg}$ doses for images acquired for $300 \mathrm{sec}$. The $\mathrm{Q}_{\mathrm{H}, 10 \mathrm{~mm}} / \mathrm{N}_{\mathrm{B}, 10 \mathrm{~mm}}$ values at 2.0

$45 \mathrm{MBq} / \mathrm{kg}$ for images acquired for $120 \mathrm{sec}$ were $3.8(\mathrm{GF})$ and 3.5 (CaLM Mild), which met the criterion (> 2.8), and

46 the RCs of 0.73 (GF) and 0.98 (CaLM Mild) for the 10-mm hot sphere, also satisfied the criterion (> 0.38). Visual

47 detectability at all doses met the criterion at $120 \mathrm{sec}$.

\section{Conclusions}

49 The quality of semiconductor digital PET/CT images was good at doses below the current standard.

50 Key words: digital PET/CT, dose, phantom, semiconductor, ${ }^{18} \mathrm{~F}-\mathrm{FDG}$

\section{Background}

53 Positron emission tomography (PET) using 2-deoxy-2[ $\left.{ }^{18} \mathrm{~F}\right]$ fluoro-D-glucose $\left({ }^{18} \mathrm{~F}\right.$-FDG) is widely applied to

54 diagnose cancer and evaluate therapeutic effects $(1,2)$.

55 Newer digital PET/computed tomography (PET/CT) systems include semiconductor devices for detectors. The

56 digital semiconductor. "Cartesion Prime” PET system (Canon Medical Systems Corp., Otawara, Japan) was installed

57 in our hospital during November 2020, and it has since been applied to stage and diagnose tumor recurrence and

58 metastasis (3). This system uses cerium-doped lutetium yttrium orthosilicate (LYSO) scintillators, silicon

59 photomultipliers (SiPM) semiconductor photosensors as detectors, and photomultiplier tubes. The system delivers

60 better image quality over shorter acquisition periods than conventional analog PET systems that have photomultiplier

61 tubes. One feature of the new system is that the scintillator and semiconductor device are coupled in a one-to-one

62 structure, which eliminates the need for positional (Anger) calculation, and the time of flight (TOF) time resolution 
63 is far better than that of analog PET systems, resulting in improved sensitivity.

64 A diagnostic reference level (DRL) has been proposed to internationally optimize radiation protection (4). Patients

65 would benefit from lower doses of radiation, whereas high doses that are unnecessary for diagnosis are harmful to

66 patients. However, a minimum dose for image acquisition has not been established. The standard dose of ${ }^{18} \mathrm{~F}$-FDG

67 required to assess tumor glucose metabolism on ${ }^{18} \mathrm{~F}$ PET/CT images is $3.7 \mathrm{MBq} / \mathrm{kg}$ according to the current Japanese

68 guidelines (5). However, this standard has not significantly changed since the early 2000s, when analog PET/CT was

69 the mainstream, whereas digital PET/CT is becoming more prevalent (6). Digital PET/CT is likely to provide better

70 image quality at lower doses than conventional PET/CT because of the features described above. Therefore, the

71 present study aimed to determine whether the quality of digital ${ }^{18} \mathrm{~F}-\mathrm{FDG}$ PET/CT images of tumor glycolytic

72 metabolism could be maintained at doses below the current guidelines using phantoms $(7,8)$.

\section{1. Methods}

\subsection{Equipment used and phantom preparation}

75 The PET/CT system was a Cartesion Prime (Canon Medical Systems Corp., Otawara, Japan) equipped with an 80- 
Table 1. Characteristics of semiconductor digital PET/CT systems.

\begin{tabular}{cc}
\hline PET characteristics & Cartesion Prime \\
\hline Detector material & LYSO $(\mathrm{Lu}-\mathrm{based})$ \\
Crystal size & $4.1 \times 4.1 \times 20 \mathrm{~mm}$ \\
Detector diameter & $780 \mathrm{~mm}$ \\
Axial field of view & $270 \mathrm{~mm}$ \\
Number of image planes & 128 \\
Sensitivity & $13.0 \mathrm{cps} / \mathrm{kBq}$ \\
TOF resolution & $<280 \mathrm{ps}$ \\
\hline
\end{tabular}

\section{$89 \quad 1.2$ PET /CT imaging and image reconstruction}

90 According to the Japanese guidelines, the background radioactivity concentration in the region is $2.53 \mathrm{kBq} / \mathrm{mL}$

91 when $3.7 \mathrm{MBq} / \mathrm{kg}$ of ${ }^{18} \mathrm{~F}-\mathrm{FDG}$ is administered to a person weighing $60 \mathrm{~kg}$ (standard body weight in Japan), and

92 images are acquired from 1 hour thereafter (8). We designed a phantom with background levels of 2.53, 1.73, and

$93 \quad 1.34 \mathrm{kBq} / \mathrm{mL}$ (equivalent to 3.7 [standard], 2.5, and $2.0 \mathrm{MBq} / \mathrm{kg}$ doses, respectively) with spheres containing 4-fold

94 more ${ }^{18} \mathrm{~F}$ radioactivity than each background.

95 Images were acquired from the phantom in list-mode for 30 minutes and cut out at intervals of $30 \mathrm{sec} / \mathrm{bed}$ in the

96 range of $30-300 \mathrm{sec} / \mathrm{bed}$ to evaluate image quality. The data were reconstructed at $30 \mathrm{~min} / \mathrm{bed}$ for quantitative

97 evaluation. Images were reconstructed using three-dimensional Ordered Subset Expectation Maximization (3D-

98 OSEM) with 12 subsets, 3 iterations, a $336 \times 336$ matrix and 2.11-mm pixels. Computed tomography attenuation

99 was corrected using TOF, and noise was processed using a Gaussian filter at FWHM $4 \mathrm{~mm}$ and the Clear adaptive

100 Low-noise Method (CaLM), which is based on the non-local-mean (NLM) method (9). The CT imaging conditions 


\subsection{Evaluation indices}

105 The ability to draw a $10-\mathrm{mm}$ hot sphere and image noise characteristics in the background was evaluated. The

following physical indices were calculated: \% background variability $\left(\mathrm{N}_{\mathrm{B}, 10 \mathrm{~mm}}\right), \%$ contrast of a $10-\mathrm{mm}$ hot sphere

$107\left(\mathrm{Q}_{\mathrm{H}, 10 \mathrm{~mm}}\right)$, coefficient of variation of the background $\left(\mathrm{CV}_{\text {background }}\right)$, and the ratio of $\mathrm{Q}_{\mathrm{H}, 10 \mathrm{~mm}}$ to $\mathrm{N}_{\mathrm{B}, 10 \mathrm{~mm}}\left(\mathrm{Q}_{\mathrm{H}, 10 \mathrm{~mm}} / \mathrm{N}_{\mathrm{B}, 10}\right.$ $\mathrm{mm})$. The recovery coefficient $(\mathrm{RC})$ of each sphere was calculated using the data derived from $30 \mathrm{~min} / \mathrm{bed}$.

109 The RC was calculated by placing a region of interest (ROI) in the slice with the most hot spheres (Figure 1) as 110 follows

$$
R C=\frac{C_{j}}{C_{37 \mathrm{~mm}}} \quad \text { Eq. } 1 .
$$

112 where $\mathrm{Cj}$ is the maximum total value for each hot sphere and $\mathrm{C}_{37 \mathrm{~mm}}$ is the maximum total for the $37-\mathrm{mm}$ sphere.

113 Twelve circular ROIs of $10 \mathrm{~mm}$ spheres were placed on five slices $( \pm 1$ and $\pm 2 \mathrm{~cm})$ where each hot sphere was most

114 clearly evident (Figure 1), then $\mathrm{N}_{\mathrm{B}, 10 \mathrm{~mm}}$ was calculated using the average of the coefficient of variation for each slice 115 as:

$$
N_{B, 10 \mathrm{~mm}}=\frac{S D_{10 \mathrm{~mm}}}{C_{B, 10 \mathrm{~mm}}} \times 100 \% \quad \text { Eq. } 2 .
$$




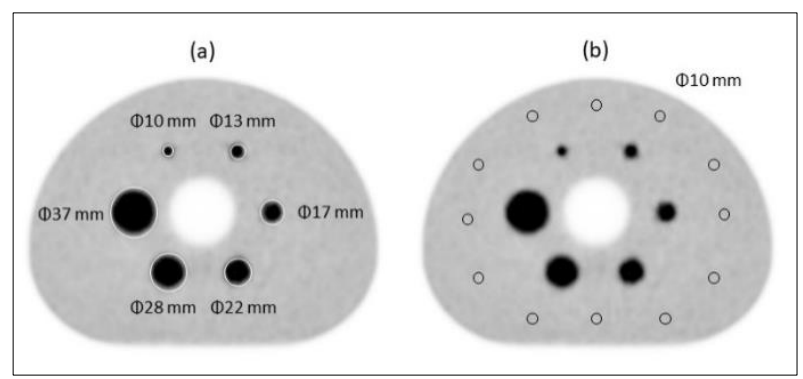

Figure 1. ROI placement.

Layouts for (a) SUV and RC, and (b) $\mathrm{N}_{\mathrm{B}, 10 \mathrm{~mm}}$ measurements.

126 Here, $\mathrm{SD}_{\mathrm{B}, 10 \mathrm{~mm}}$ is the standard deviation in each ROI set in the background (BG), and $\mathrm{C}_{\mathrm{B}, 10 \mathrm{~mm}}$ and $\mathrm{SD}_{10 \mathrm{~mm}}$ represent 127 the average count and the standard deviation in the ROI with a diameter of $10 \mathrm{~mm}$ in the $\mathrm{BG}$. The $\mathrm{SD}_{10 \mathrm{~mm}}$ is calculated 128 as:

$$
S D_{j}=\sqrt{\frac{\sum_{K=1}^{K}\left(C_{B, j, k}-C_{B, j}\right)^{2}}{(K-1)}}
$$

Eq. 3.

where $\mathrm{j}$ is $10 \mathrm{~mm}$ and $\mathrm{K}$ is 60 (12 ROIs on five slices, 60 in total). The $\mathrm{Q}_{\mathrm{H}, 10 \mathrm{~mm}}$ was calculated by measuring the 10$\mathrm{mm}$ hot sphere and the BG using a circular ROI with a diameter of $10 \mathrm{~mm}$ in a slice where the hot sphere was the most clearly evident as:

$$
Q_{H, 10 \mathrm{~mm}}=\frac{C_{H, 10 \mathrm{~mm}} / C_{H, 10 \mathrm{~mm}-1}}{\alpha_{H} / \alpha_{B}-1} \times 100 \% \quad \text { Eq. } 4 .
$$

134 where $\mathrm{Q}_{\mathrm{H}, 10 \mathrm{~mm}}$ is the average pixel value in the $\mathrm{ROI}$ for the $10 \mathrm{~mm}$ hot sphere, $\mathrm{C}_{\mathrm{B}, 10 \mathrm{~mm}}$ is the average pixel value in 135 the BG calculated from the circular ROI of the 12 spheres with a diameter of $10 \mathrm{~mm}$, and $\alpha_{\mathrm{H}}$ and $\alpha_{\mathrm{B}}$ are the 136 radioactivity concentrations $(\mathrm{Bq} / \mathrm{mL})$, in the hot sphere and $\mathrm{BG}$, respectively. Twelve circular ROIs of 37-mm 137 spheres were set in the BG where a slice contained clear representations of all sizes of spheres to determine

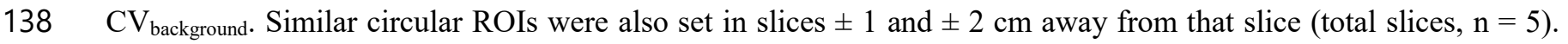




$$
C V_{\text {background }}=\text { mean of }\left[\frac{S D_{37} \mathrm{~mm}}{C_{B, 37 \mathrm{~mm}}} \times 100\right] \% \quad \text { Eq. } 5 .
$$

141 Here, $\mathrm{C}_{\mathrm{B}, 37 \mathrm{~mm}}$ and $\mathrm{SD}_{37} \mathrm{~mm}$ are the mean counts and standard deviation, respectively, in each ROI of 37-mm

142 spheres in the BG. The $\mathrm{SD}_{37 \mathrm{~mm}}$ in each ROI was calculated using Eq. 3, where $\mathrm{j}$ is $37 \mathrm{~mm}$ and $\mathrm{k}$ is the number of

143 pixels in each ROI. Five radiologists and a nuclear medicine specialist visually evaluated the ability to define the 10-

$144 \mathrm{~mm}$ hot sphere on reconstructed images from $30-300$ at 30 -sec intervals using a workstation terminal for reading

145 clinical PET images. Images were displayed using an invert grayscale as the color look-up table. The lower and upper

146 limits of the display window level were fixed at SUV $=0$ and 4, respectively. All image slices were visually evaluated

147 by sequentially displaying the images acquired over the shortest period. Visibility of the 10-mm hot sphere was scored

148 from 0 to 2 as not identifiable, identifiable with noise and identifiable, respectively. When $>50 \%$ of the evaluators

149 judged the $10-\mathrm{mm}$ hot sphere as identifiable, an average score of $\geq 1.5$ was taken as the criterion for satisfying the

150 evaluation (7).

\section{2. Results}

\section{$2.1 \mathrm{~N}_{\mathrm{B}, 10 \mathrm{~mm}}$}

153 Figures 2 and 3 show the relationship between $\mathrm{N}_{\mathrm{B}, 10 \mathrm{~mm}}$ and dose. The noise trends were similar between the

154 Gaussian filter and CaLM Mild from 30 to $300 \mathrm{sec}$, and the noise increased with decreasing dose. The $3.7 \mathrm{MBq} / \mathrm{kg}$ 155 dose was 5.5\% for the Gaussian filter and 5.5\% for CaLM Mild on images acquired for $270 \mathrm{~s}$, which satisfied the 156 guideline value of $<5.6 \%(7,8)$. At doses of 2.5 and $2.0 \mathrm{MBq} / \mathrm{kg}$, the respective $\mathrm{N}_{\mathrm{B}, 10 \mathrm{~mm}}$ values determined from 157 images acquired over $300 \mathrm{sec}$ were $6.9 \%$ and $7.6 \%$, for the Gaussian filter, and $7.1 \%$ and $7.4 \%$ for CaLM Mild. These results did not meet the guideline values. 


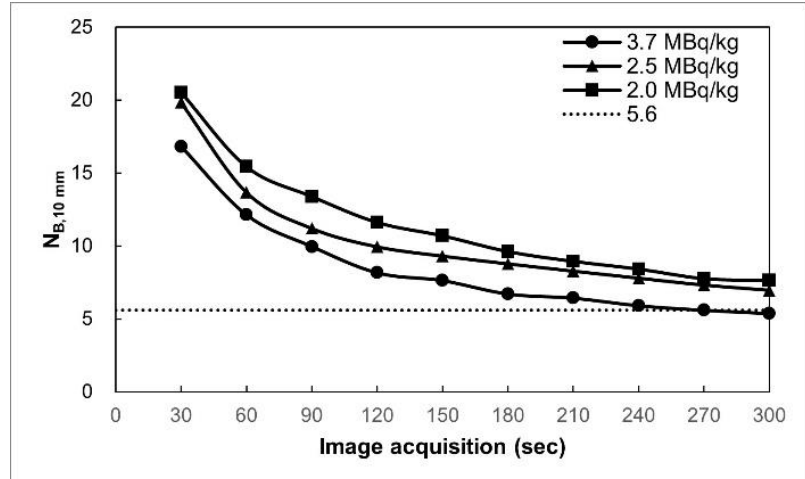

Figure 2. $\mathrm{N}_{\mathrm{B}, 10 \mathrm{~mm}}$ Gaussian filter $\mathrm{FWHM}=4$.

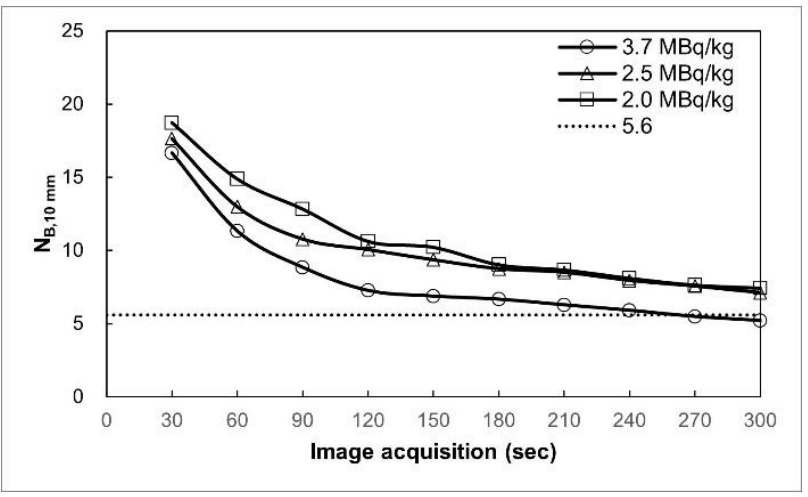

Figure 3. $\mathrm{N}_{\mathrm{B}, 10 \mathrm{~mm}}$ CaLM Mild.

170 Figures 4 and 5 show the relationship between $\mathrm{Q}_{\mathrm{H}, 10 \mathrm{~mm}}$ and doses of 2.0, 2.5, and $3.7 \mathrm{MBq} / \mathrm{kg}$. Values for $\mathrm{Q}_{\mathrm{H}, 10 \mathrm{~mm}}$

171 were higher in the Gaussian filter after acquisition for $120 \mathrm{~s}$. Values were higher for CaLM Mild in the order of 2.0,

1723.7 , and $2.5 \mathrm{MBq} / \mathrm{kg}$ doses in images acquired for $120-240 \mathrm{sec}$, and the order of $2.5,2.0$, and 3.7 MBq/kg between

173240 and $300 \mathrm{sec}$ thereafter. Values determined using CaLM Mild surpassed those in the Gaussian filter at 120 sec,

174 and $\mathrm{Q}_{\mathrm{H}, 10 \mathrm{~mm}}$ continued to increase until $300 \mathrm{sec}$. 


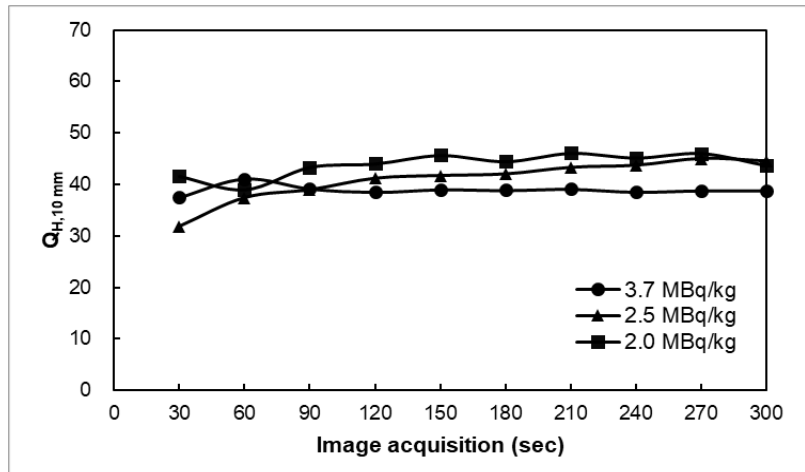

Figure 4. $\mathrm{Q}_{\mathrm{H}, 10 \mathrm{~mm}}$ Gaussian filter $\mathrm{FWHM}=4$.

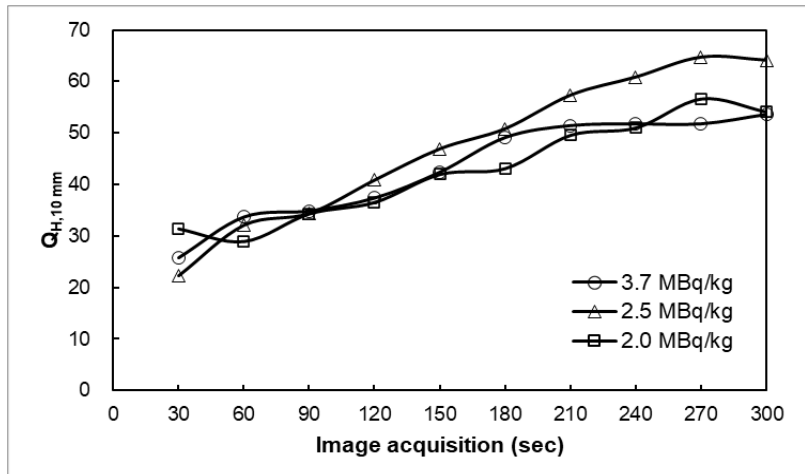

Figure 5. $\mathrm{Q}_{\mathrm{H}, 10 \mathrm{~mm}}$ CaLM Mild.

\subsection{CV background}

189 Figures 6 and 7 show the relationship between $\mathrm{CV}_{\text {background }}$ and dose. The trends for the Gaussian filter and CaLM

Mild were similar between 30 and $300 \mathrm{sec}$. At a dose of $3.7 \mathrm{MBq} / \mathrm{kg}$, The CV background was $9.9 \%$ and $10 \%$ for the

191 Gaussian filter in images collected for $270 \mathrm{~s}$, and $\leq 10 \%$ for CaLM Mild when images were acquired for $300 \mathrm{sec}(8)$.

192 However, at doses of 2.5 and $2.0 \mathrm{MBq} / \mathrm{kg}, \mathrm{CV}_{\text {background }}$ values were $11 \%$ and $12 \%$ for the Gaussian filter, and $13 \%$ 193 for CaLM Mild, respectively, when images were acquired for $300 \mathrm{sec}$. These results did not meet the guideline values. 


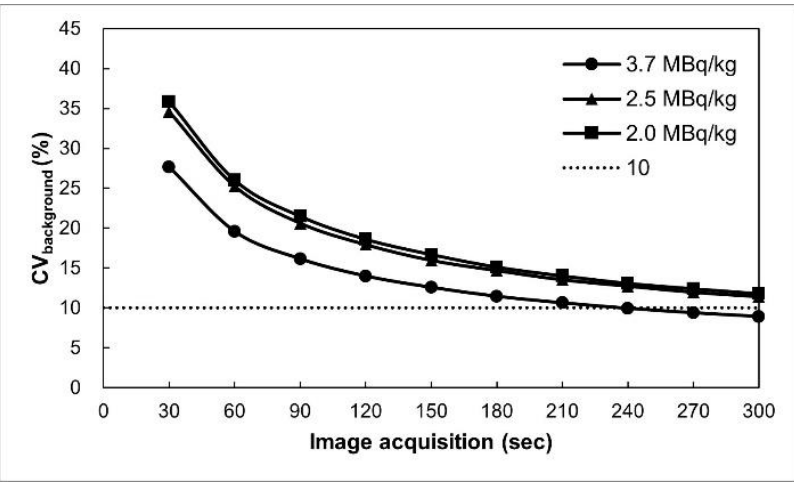

Figure 6. $\mathrm{CV}_{\text {background }}$ Gaussian filter $\mathrm{FWHM}=4$.

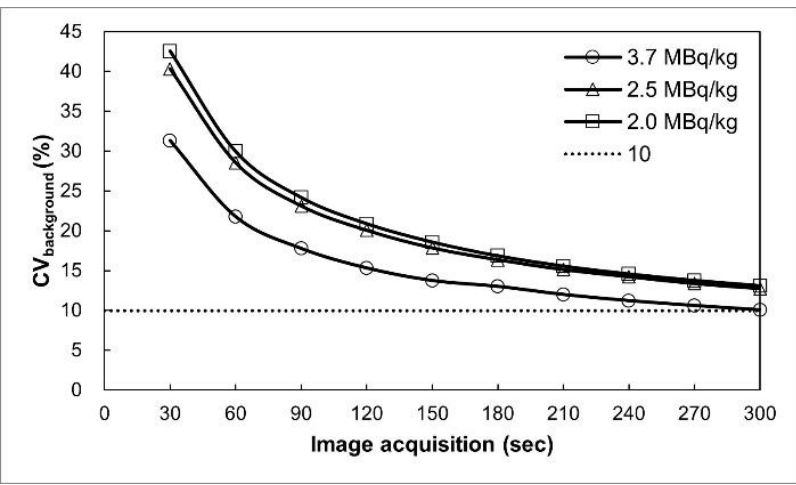

Figure 7. $\mathrm{CV}_{\text {background }}$ CaLM Mild.

\section{$2.4 \mathrm{Q}_{\mathrm{H}, 10 \mathrm{~mm}} / \mathrm{N}_{\mathrm{B}, 10 \mathrm{~mm}}$}

208 Figures 8 and 9 show the relationship between $\mathrm{Q}_{\mathrm{H}, 10 \mathrm{~mm}} / \mathrm{N}_{\mathrm{B}, 10 \mathrm{~mm}}$ and dose. The trends in these values were similar

209 between the Gaussian filter and CaLM Mild between images acquired for 30 to $300 \mathrm{sec}$ and increased along with the

210 dose. When the dose was $3.7 \mathrm{MBq} / \mathrm{kg}$ and images were acquired for $60 \mathrm{~s}$, the $\mathrm{Q}_{\mathrm{H}, 10 \mathrm{~mm}} / \mathrm{N}_{\mathrm{B}, 10 \mathrm{~mm}}$ determined using the

211 Gaussian filter and CaLM Mild were 3.4 and 3.0, respectively, which satisfied the guideline standard of $>2.8$. When

212 the dose was $2.0 \mathrm{MBq} / \mathrm{kg}$ and the acquisition duration was $120 \mathrm{sec}$, the values obtained using the Gaussian filter and

213 CaLM Mild were 3.8 and 3.5, respectively, which exceeded the reference values $(7,8)$. 


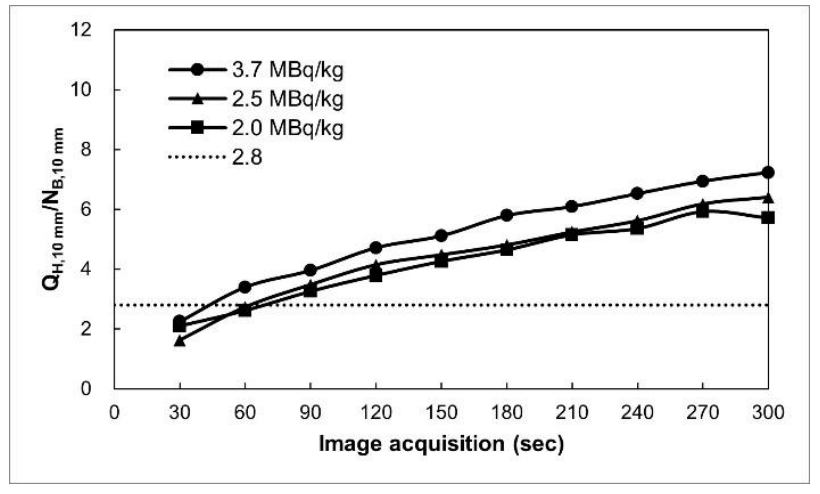

Figure 8. $\mathrm{Q}_{\mathrm{H}, 10 \mathrm{~mm}} / \mathrm{N}_{\mathrm{B}, 10 \mathrm{~mm}}$ Gaussian filter $\mathrm{FWHM}=4$.

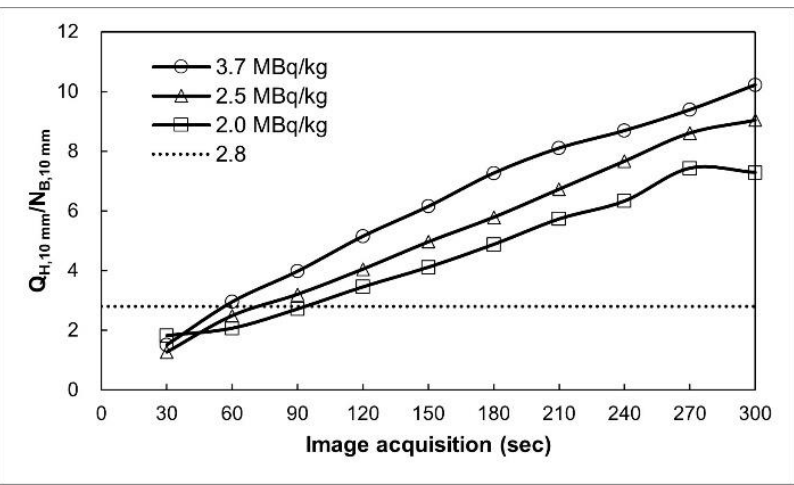

Figure 9. $\mathrm{Q}_{\mathrm{H}, 10 \mathrm{~mm}} / \mathrm{N}_{\mathrm{B}, 10 \mathrm{~mm}}$ CaLM Mild.

\subsection{Recovery coefficients}

227 Figures 10 and 11 show the relationship between RC and dose.

228 Recovery coefficients determined for $10-\mathrm{mm}$ hot spheres equivalent to a dose of $2.0 \mathrm{MBq} / \mathrm{kg}$ using the Gaussian

229 filter and CaLM Mild were high at 0.73 and 0.98 , respectively. All other concentrations of the hot spheres exceeded

230 the guideline standard of $>0.38(7,8)$.

231 In addition, the partial volume effect (PVE) determined using the Gaussian filter was improved by $34 \%$ from 0.73 


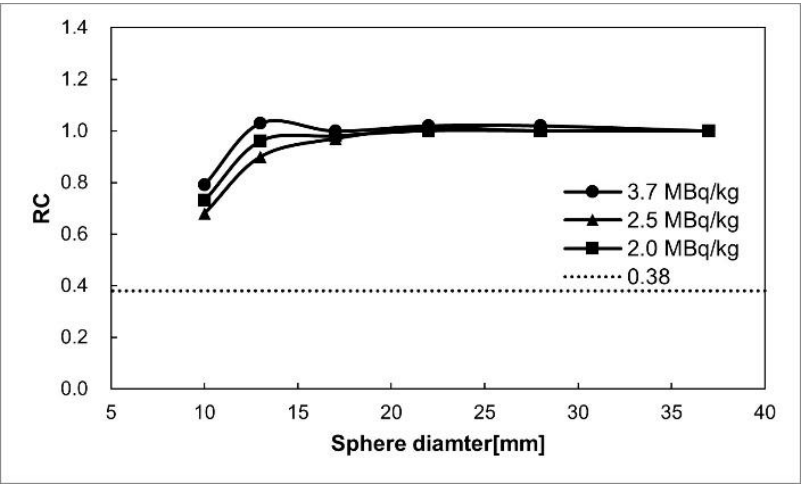

Figure 10. Recovery coefficients: Gaussian filter FWHM $=4$.

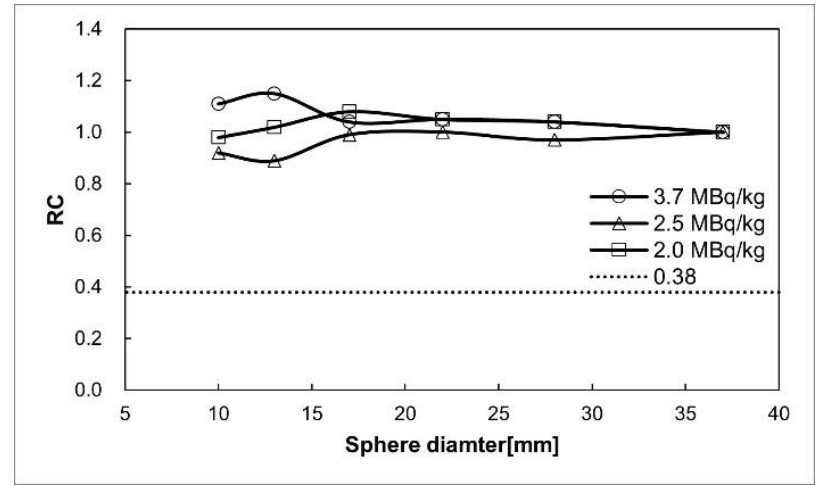

Figure 11. Recovery coefficients CaLM Mild

\section{2-6 Visual evaluation of detectability}

246 The ability of the Gaussian filter (FWHM $4 \mathrm{~mm}$ ) and CaLM Mild to visualize the 10-mm hot sphere at 3.7, 2.5 and

$2472.0 \mathrm{MBq} / \mathrm{kg}$ doses met the standard at 60, 90, and 120 seconds, respectively (Table 2, Fig. 12).

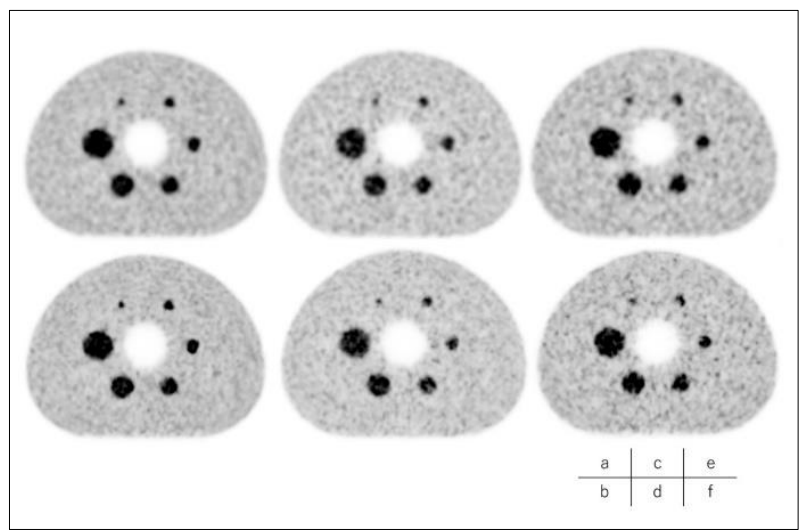

Figure 12. PET images acquired from body phantom for $120 \mathrm{sec}$. Upper and lower rows, Gaussian filter at FWHM 


\begin{tabular}{cccccccccccc}
\hline \multirow{2}{*}{ Dose (MBq/kg) } & \multicolumn{10}{c}{ Acquisition period (sec) } \\
\cline { 3 - 11 } & Reconstruction mode & $\mathbf{3 0}$ & $\mathbf{6 0}$ & $\mathbf{9 0}$ & $\mathbf{1 2 0}$ & $\mathbf{1 5 0}$ & $\mathbf{1 8 0}$ & $\mathbf{2 1 0}$ & $\mathbf{2 4 0}$ & $\mathbf{2 7 0}$ & $\mathbf{3 0 0}$ \\
\hline \multirow{2}{*}{3.7} & GF & 1.4 & 2 & 2 & 2 & 2 & 2 & 2 & 2 & 2 & 2 \\
& CaLM Mild & 0.8 & 2 & 2 & 2 & 2 & 2 & 2 & 2 & 2 & 2 \\
\multirow{2}{*}{$\mathbf{2 . 5}$} & GF & 0 & 0.8 & 1.6 & 2 & 2 & 2 & 2 & 2 & 2 & 2 \\
& CaLM Mild & 0 & 1 & 1.8 & 1.8 & 2 & 2 & 2 & 2 & 2 & 2 \\
\multirow{2}{*}{$\mathbf{2 . 0}$} & GF & 0 & 0.8 & 1 & 2 & 2 & 2 & 2 & 2 & 2 & 2 \\
& CaLM Mild & 0.2 & 0.4 & 1.2 & 1.8 & 2 & 2 & 2 & 2 & 2 & 2 \\
\hline
\end{tabular}

GF, Gaussian filter (FWHM 4 mm)

\section{Discussion}

258 The present study investigated the ability of a semiconductor digital PET/CT system to generate quality images

259 from a phantom with simulated standard and low doses (4).

260 The results for $\mathrm{N}_{\mathrm{B}, 10 \mathrm{~mm}}$ show that the noise characteristics required $270 \mathrm{sec}$ to meet the guideline standard even at a

261 dose equivalent to $3.7 \mathrm{MBq} / \mathrm{kg}$. In this system, the detector is large (270 $\mathrm{mm}$ in the body axis direction), and an

262 increase in random components is a problem. The probability of an accidental coincidence is proportional to the

263 width of the coincidence window.

264 The ability of the Gaussian filter and CaLM Mild to visualize the 10-mm hot sphere at doses of 3.7, 2.5, and 2.0

$265 \mathrm{MBq} / \mathrm{kg}$ met the guideline standard at 60, 90, and $120 \mathrm{sec}$, respectively (Fig. 12; Table 2).

266 To cope with this problem, the coincidence coefficient window was narrowed to $3.2 \mathrm{nsec}$ to eliminate more

267 coincidences. More sensitive PET detection is associated with lower contrast. If the number of contingent

268 coincidences is smaller than the true number of coincidences, the image has good contrast. Therefore, the detection 
269 sensitivity is thought to be maximal at $\sim 240 \mathrm{~s}$, and a dose of $3.7 \mathrm{MBq} / \mathrm{kg}$ is required to meet the reference value of

$270 \mathrm{~N}_{\mathrm{B}, 10 \mathrm{~mm}}$. The $\mathrm{Q}_{\mathrm{H}, 10 \mathrm{~mm}}$ depended on the radioactivity concentration in the $\mathrm{BG}$ for the Gaussian filter. That is, the

271 variability was large at a lower dose and acquisition periods of 30-90 sec but decreased when either the acquisition

272 period or the dose was increased. These findings suggested that sufficient counts are necessary to obtain stable

273 contrast. The Gaussian filter resulted in a higher $\mathrm{Q}_{\mathrm{H}, 10 \mathrm{~mm}}$ at lower doses, whereas $\mathrm{Q}_{\mathrm{H}, 10 \mathrm{~mm}}$ did not significantly differ

274 with the dose in CaLM Mild. This might be because CaLM is based on the NLM method, and the difference between

275 signal and noise is small at shorter acquisition periods. Therefore, a longer acquisition period and more counts

276 improved the discrimination between signal and noise components in CaLM Mild, but the trend was steeper than that

277 of the Gaussian filter. The reason for this is that Gaussian filter and CaLM Mild have the same amount of noise as

278 indicated by the $\mathrm{N}_{\mathrm{B}, 10 \mathrm{~mm}}$, whereas the $\mathrm{Q}_{\mathrm{H}, 10 \mathrm{~mm}}$ in CaLM is based on the NLM method, which tends to increase the

279 contrast as the acquisition period lengthens. The reason for this is that contrast continues to increase as the acquisition

280 time increases. Visual descriptive scores of $\geq 1.5(>50 \%$ of the evaluators judged the $10-\mathrm{mm}$ hot sphere as

281 identifiable) were improved by extending the acquisition period, and scores tended to increase at higher, than at lower

282 doses with shorter acquisition periods. This might be because a higher dose and longer acquisition period leads to

283 more true coincidences that can be used for reconstructing images with better quality. However, $2.0 \mathrm{MBq} / \mathrm{kg}$ and

284 image acquisition for $120 \mathrm{sec}$, which is the clinical practice, was sufficient to distinguish the $10-\mathrm{mm}$ hot sphere, and

285 the high contrast signal was not buried by background noise.

\section{Conclusions}


288 We evaluated the image quality of ${ }^{18} \mathrm{~F}$-FDG tumor glycolysis using a semiconductor digital PET/CT system at lower

289 doses than the current standard. The evaluation of physical parameters and visual assessment of the acquired images

290 were good even at low doses. Therefore, small $(\sim 10 \mathrm{~mm})$ lesions should be detectable within clinical acquisition

291 periods at doses below the current standard (4).

\section{Abbreviations}

293 FDG: Fluorodeoxyglucose; CT: Computed tomography; PET: Positron emission tomography; DRL: Diagnostic 294 reference level; 3D-OSEM: three-dimensional Ordered Subset Expectation Maximization; CaLM: Clear adaptive 295 Low-noise Method; NLM: Non-local-mean method; RC: Recovery coefficient; ROI: Region of interest; SUV: 296 Standardized uptake value; BG: Background; SD: Standard deviation

\section{Acknowledgements}

$298 \quad$ Not applicable.

\section{Author's contributions}

$300 \quad$ Not applicable.

\section{Author's information}

$302 \quad$ Not applicable.

\section{$303 \quad$ Funding}

$304 \quad$ Not applicable.

\section{Availability of data and materials}

$306 \quad$ Not applicable. 
308 Ethics approval and consent to participate

309 This study was based on a phantom. Thus, approval by our institutional Ethics Committee was not required.

310 Consent for publication

311 Not applicable.

312 Competing interests

313 The datasets generated and analysed during the current study are not publicly available due to the large volume of

314 DICOM data, but are available from the corresponding author on reasonable request.

\section{Author details}

316 Yuya Shirakawa

317 Radiological Technologist

318

319 Department of Radiology, Kyorin University Hospital,

320 6-20-2 Shinkawa, Mitaka, Tokyo, Japan 181-8611

321

322 E-mail: yuya_shirakawa@ks.kyorin-u.ac.jp

323 Tel: +81-422-47-5511

324 Fax: $+81-422-76-0361$

\section{REFERENCES}

326 1) Lu Z, Lin M, Downe $\mathrm{P}$, et al. The prognostic value of mid-and post-treatment [(18) F] fluorodeoxyglucose (FDG) positron emission tomography (PET) in indolent follicular lymphoma. Ann Nucl Med 2014; $28(8): 805-$ 811.

2) Pauwels EK, Coumou AW, Kostkiewicz M, et al. [18F]fluoro-2-deoxy-d-glucose positron emission tomography/computed tomography imaging in oncology: initial staging and evaluation of cancer therapy. Med 
332 3) Daisaki H, Kojima Y, et al. New digital Cartesion Prime PET/CT scanner: Image Quality and SUV Comparison 333 with the non-digital Celesteion PET/CT scanner. Journal of Nuclear Medicine. Vol. 61(1): 2020.

334 4) Japan Network for Research and Information on Medical Exposure (J-RIME), et al. National diagnostic 335 reference levels in Japan (2020) - Japan DRLs 2020-. 2020.

336 5) Japanese Society of Nuclear Medicine, Japanese Society of Nuclear Medicine PET Nuclear Medicine 337 Subcommittee. FDG-PET Cancer Screening Guidelines, 3rd Edition. 2019;10

338 6) FDG PET, PETCT Clinical Practice Guideline 2020 The Japanese Society of Nuclear Medicine

339 7) Fukukita H, et al. Japanese guideline for the oncology FDG-PET/CT date acquisition protocol : synopsis of version 2.0. Ann Nucl Med 28(7):693-705,2014

341 8) The Japanese Society of Nuclear Medicine, Committee on PET Nuclear Medicine: Phantom Study Procedures for Whole Body PET Imaging Using 18F-FDG, 3rd Edition, 2017

343 9) Qi W, Xia T, Niu X, et al. A Non-Local Means Post-Filter with Spatially Adaptive Filtering Strength for WholeBody PET. IEEE Nuclear Science Symposium and Medical Imaging Conference (NSS/MIC) 2015

10) Matsumoto K, Dasani Y, et al. Positron Emission Tomography: Image Quality Standardization and Accuracy 